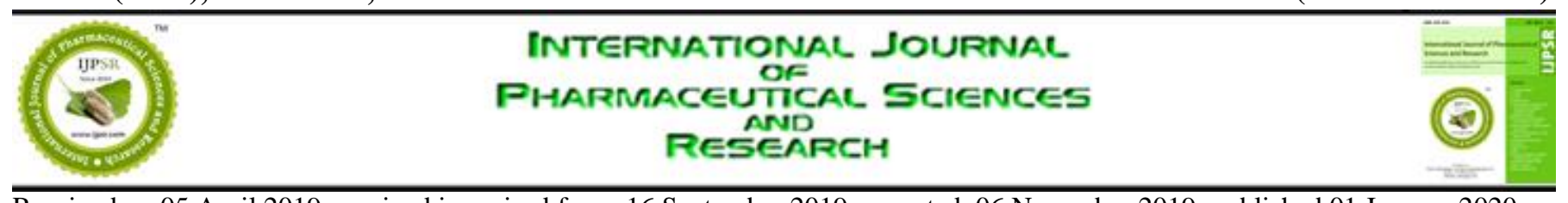

Received on 05 April 2019; received in revised form, 16 September 2019; accepted, 06 November 2019; published 01 January 2020

\title{
ANALYTICAL METHOD DEVELOPMENT AND VALIDATION FOR SIMULTANEOUS ESTIMATION OF ERTUGLIFLOZIN AND METFORMIN HCI IN BULK AND PHARMACEUTICAL DOSAGE FORM BY HPLC
}

Syed Wajahat Shafaat ${ }^{*}{ }^{1}$, Aejaz Ahmed ${ }^{1}$, G. J. Khan ${ }^{1}$, Shaikh Anas ${ }^{1}$ and Absar A. Qureshi ${ }^{2}$

Department of Quality Assurance ${ }^{1}$, Ali-Allana College of Pharmacy, Akkalkuwa, Nandurbar - 425415, Maharashtra, India.

Department of Pharmacology ${ }^{2}$, College of Pharmacy, King Khalid University, ABHA kingdom of Saudi Arabia.

Keywords:

Ertugliflozin, Metformin hydrochloride, HPLC, Method development

Correspondence to Author:

Syed Wajahat Shafaat

Department of Quality Assurance, Ali-Allana College of Pharmacy, Akkalkuwa, Nandurbar - 425415, Maharashtra, India.

E-mail: sdwajahat07@gmail.com
ABSTRACT: Analytical method for simultaneous estimation of Ertugliflozin (ERT) and Metformin hydrochloride (MET) was developed and validated by high-performance liquid chromatography (HPLC) as per ICH guidelines. The drugs were injected into the inertsil C18 $(250 \times 4.6 \mathrm{~mm})$ maintained at room temp and wavelength $220 \mathrm{~nm}$. The mobile phase consists of buffer (potassium dihydrogen $\mathrm{pH} 4.0)$ and methanol $(65: 35 \mathrm{v} / \mathrm{v})$. The flow rate is maintained at $1.0 \mathrm{~mL} / \mathrm{min}$. The calibration curve was linear and regression coefficient $\left(\mathrm{R}^{2}\right)$ value was found to be 0.999 and concentration ranging from 1.5-4.5 $\mu \mathrm{g} / \mathrm{mL}$ and $100-300 \mu \mathrm{g} / \mathrm{mL}$ for Ertugliflozin and Metformin hydrochloride respectively. The LOD and LOQ of the method were found $1.04 \mu \mathrm{g} / \mathrm{mL}, 9.61 \mu \mathrm{g} / \mathrm{mL}$ and $0.0007 \mu \mathrm{g} / \mathrm{mL}, 0.006 \mu \mathrm{g} / \mathrm{mL}$ for Ertugliflozin and Metformin $\mathrm{HCl}$. The developed method was found to be simple, precise, specific, linear and accurate as validated as per USP and International Conference on Harmonization (ICH) guidelines.
INTRODUCTION: Ertugliflozin (ERT) chemical name is $(1 \mathrm{~S}, 2 \mathrm{~S}, 3 \mathrm{~S}, 4 \mathrm{R}, 5 \mathrm{~S})-5-$ [4- chloro $-3-$ [(4-ethoxyphenyl ) methyl] -6,8-dioxybicyclo [3, 2, 1] octane -2, 3, 4-triol compound with (2S) 5oxypyrrolidine - 2-carboxylic acid and molecular formula $\mathrm{C}_{22} \mathrm{H}_{25} \mathrm{ClO}_{7}$ show in Fig. 1. Ertugliflozin is inhibiter of sodium-glucose co-transporter -2 (SGLT-2) is the pro dominant transporter responsible for reabsorption of glucose from the glomerular filtrate back into the circulation. Ertugliflozin is indicated to improve glycemic in adult patients with type -2 diabetes controls ${ }^{1-3}$.

\begin{tabular}{|l|c|}
\hline QUICK RESPONSE CODE & DOI: \\
\hline & $\begin{array}{c}\text { Do.13040/IJPSR.0975-8232.11(1).226-32 } \\
\text { This article can be accessed online on } \\
\text { www.ijpsr.com }\end{array}$ \\
\hline DOI link: http://dx.doi.org/10.13040/IJPSR.0975-8232.11(1).226-32 \\
\hline
\end{tabular}

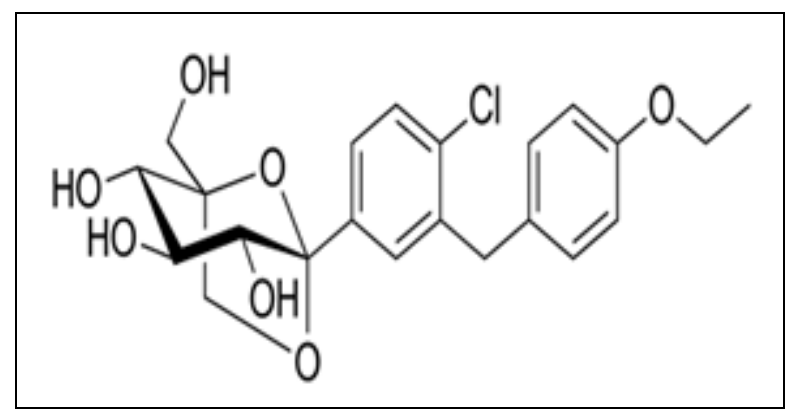

FIG. 1: ERTUGLIFLOZIN

Metformin (MET) chemical name is N, N dimethyl imido dicarboximide diamide hydrochloride and molecular formula $\mathrm{C}_{4} \mathrm{H}_{11} \mathrm{~N}_{5}$. $\mathrm{HCl}$ shows in Fig. 2 . Metformin $\mathrm{HCl}$ is oral antihyperglycemic drugs used in the management of type-2 diabetes ${ }^{4-5}$.

Combining anti-hyperglycemic agents in order to rapidly and safely achieve the best possible glycemic control is the standard of care today for the management of type 2 diabetes. 


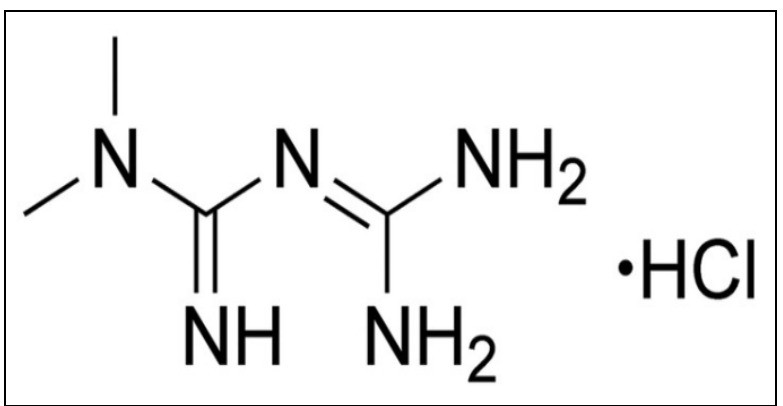

FIG. 2: METFORMIN HCl

Agents should ideally have mechanisms of actions that are complementary and that improve glycemic control without an unacceptable gain in body weight or hypoglycemia. Ertugliflozin and metformin hydrochloride (ertugliflozin/metformin, Segluromet) is a recently approved fixed-dose combination tablet containing the sodium-glucose co-transporter 2(SGLT-2) inhibitor ertugliflozin and metformin. Diabetes is a group of metabolic disorders characterized by the presence of chronic hyperglycemia by greater or lesser impairment in the metabolism of carbohydrate, lipids, and proteins.

The result is a high level of glucose in the blood the two active substances such as ertugliflozin and metformin $\mathrm{HCl}$ to lower glucose level ${ }^{6}$. SGLT-2 inhibitors are an important class of antihyperglycemic agents that are efficacious as monotherapy and in combination with other antihyperglycemic agents. Given their favorable effects on glycemic control as well as 'extraglycemic' parameters such as body weight and blood pressure, they are ideal agents for appropriate patients with type 2 diabetes. The fixed-dose combination of ertugliflozin with metformin is an effective combination that is conveniently administered and may improve medication adherence and persistence ${ }^{7}$.

Even though numerous methods are available for the estimation of metformin hydrochloride available individually and in combination with another drug, whereas five methods available for the estimation of ertugliflozin and sitagliptin no method has been reported estimation of ertugliflozin and metformin hydrochloride simultaneously ${ }^{8-16}$.

MATERIALS AND METHODS: Standard of ERT and MET $\mathrm{HCl}$ were obtained from Merck.
Buffer and methanol were obtained from Rankem. All solvent and reagent were of analytical grade.

Instrumentation: Gradient system HPLC equipped with an aligned UV detector was used throughout the analysis. The analysis column inertsil $\mathrm{C} 18250 \mathrm{~mm} \times 4.6 \mathrm{~mm}, 5 \mu$ thermo scientific was used as a stationary phase. The instrumental settings were flow of $1.0 \mathrm{~mL} / \mathrm{min}$ and injection volume $20 \mu \mathrm{L}$ column oven temperature was ambient.

Buffer Preparation: 6.8 gm Potassium dihydrogen phosphate buffer was transferred to $1000 \mathrm{~mL}$ beaker, and $800 \mathrm{~mL}$ water was added shacked to dissolve, and volume was made up with water, $\mathrm{pH}$ 4.0 was adjusted with diluted o-Phosphoric acid.

MET Standard Stock Solution $(2000 \mu \mathrm{g} / \mathrm{mL})$ : Accurately weighed $200 \mathrm{mg}$ of MET and Transferred to $100 \mathrm{~mL}$ volumetric flask and volume were made up with the Diluents.

ERT Standard Stock Solution (30 $\mu \mathrm{g} / \mathrm{mL})$ : Accurately weighed $30 \mathrm{mg}$ of ERT and Transferred to $100 \mathrm{~mL}$ volumetric flask and volume were made up with the Diluents, Transfer $1 \mathrm{~mL}$ of this solution to $10 \mathrm{~mL}$ volumetric flask and volume was made up with the Diluents.

Standard Working Solution (MET $200 \mu \mathrm{g} / \mathrm{mL}$, ERT $3 \mu \mathrm{g} / \mathrm{mL}$ ): $1 \mathrm{~mL}$ of standard stock solution was transferred to $10 \mathrm{~mL}$ volumetric flask and volume was made up with the diluents.

Optimization of Chromatographic Conditions: a various combination of mobile phase was screened with respect to resolution, theoretical plate, capacity factor, and other system suitability parameters. finally the separation was performed with freshly prepared mobile phase consist of buffer (ph 4.0): methanol in the ratio of 65:35 at flow rate of $1.0 \mathrm{~mL} / \mathrm{min}$. $220 \mathrm{~nm}$ wavelength, injection volume of $20 \mathrm{ul}$ temperature was maintained during the entire process to obtain symmetric peak of MET $\mathrm{HCl}$ and ERT.

Method of Validation: ${ }^{17-18}$

System Suitability: System suitability test is a fundamental part of liquid chromatography. It ensures that system is working correctly. The standard solution of ERT and MET $\mathrm{HCl}$ was 
injected into the chromatographic system and recorded the chromatogram. System suitability parameters such as number of theoretical plates, retention time, and tailing factor were calculated.

Linearity: Linearity of the method was performed by analyzing a standard solution of MET HCL and ERT to obtain a solution in the concentration range is $100-300 \mu \mathrm{g} / \mathrm{mL}$ and $1.5-4.5 \mu \mathrm{g} / \mathrm{mL}$ for MET HCL and ERT respectively. The area of each level was calculated and graph of area versus concentration was plotted. The correlation coefficient was calculated in linearity plot.

LOD (Limit of Detection) and LOQ (Limit of Quantitation) of ERT and MET HCl: LOD and LOQ of ERT and MET HCL were determining by calibration curve used to determine the method of linearity.

It may be calculated as

$$
\begin{aligned}
& \mathrm{LOD}=3.3 \times(\mathrm{SD} / \text { Slope }) \\
& \mathrm{LOQ}=10 \times(\mathrm{SD} / \text { Slope })
\end{aligned}
$$

Where; $\mathrm{SD}=$ standard deviation of response (peak area), Slope $=$ mean of slop of the calibration curve.

Precision: Precision of the method was determined by injecting six replicate of sample an unknown concentration of ERT $3 \mu \mathrm{g} / \mathrm{mL}$ and MET $\mathrm{HCl} 200$ $\mu \mathrm{g} / \mathrm{mL}$ have been analyzed by injecting into an HPLC column on the same day.

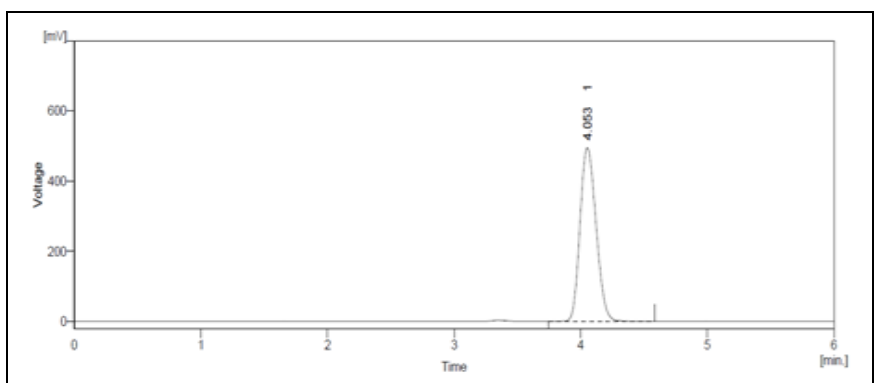

FIG. 3: CHROMATOGRAM OF STANDARD MET HCI
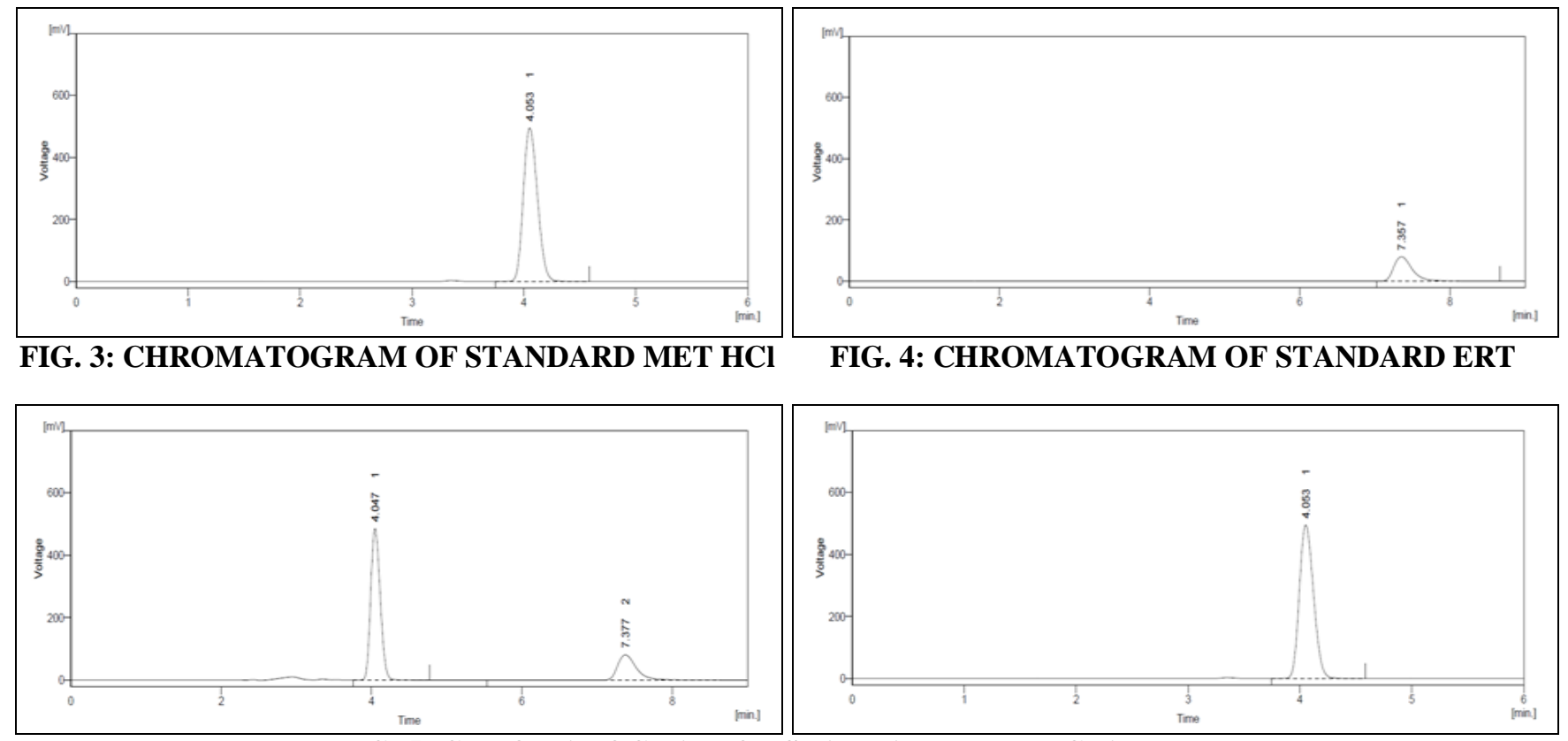

FIG. 4: CHROMATOGRAM OF STANDARD ERT

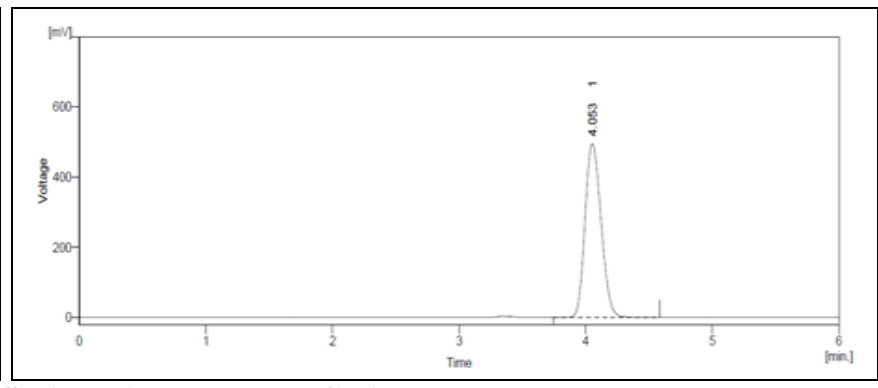

FIG. 5: CHROMATOGRAM OF STANDARD MET HCI AND ERT 
TABLE 1: RESULTS FOR SYSTEM SUITABILITY TEST

\begin{tabular}{ccc}
\hline Parameters & ERT & MET HCI \\
\hline Theoretical plates per column & 4435 & 4430 \\
Symmetry factor/tailing factor & 1.661 & 1.273 \\
Retention time (min) & 7.357 & 4.053 \\
Resolution & - & - \\
\hline
\end{tabular}

System Suitability: The system suitability was performed by injecting mix standard solution containing $200 \mu \mathrm{g} / \mathrm{mL}$ MET HCL and $3 \mu \mathrm{g} / \mathrm{mL}$ ERT in six replicates. For two of them, the peak asymmetric was $<1.5$, and the theoretical plate number is > 2000and \% RSD of ERT, and MET $\mathrm{HCl}$ was less than 2. The result indicates that the system suitability parameter is within the acceptable limit. The results are shown in Table $\mathbf{1 .}$

Linearity: The linearity of the method was established by determining the constructing calibration graph between tested calibration level and corresponding peak area for ERT and MET $\mathrm{HCl}$ in triplicate. Over a range of $1.5-4.5 \mu \mathrm{g} / \mathrm{mL}$ and $100-300 \mu \mathrm{g} / \mathrm{ml}$, respectively.

The correlation coefficient was $>0.999$ for all two drugs. The results are given in Table 2 and Fig. 6A and $\mathbf{6 B}$.

TABLE 2: LINEARITY DATA FOR ERT AND MET

\begin{tabular}{|c|c|c|c|c|}
\hline & \multicolumn{2}{|c|}{ Metformin HCl } & \multicolumn{2}{|c|}{ Ertugliflozin } \\
\hline S. no. & Concentration $\mu \mathrm{g} / \mathrm{mL}$ & Area & Concentration $\mu \mathrm{g} / \mathrm{mL}$ & Area \\
\hline 01 & 100 & 2171.289 & 1.5 & 682.424 \\
\hline 02 & 150 & 3205.757 & 2.25 & 1015.305 \\
\hline 03 & 200 & 4383.295 & 3 & 1388.885 \\
\hline 04 & 250 & 5397.235 & 3.75 & 1710.713 \\
\hline 05 & 300 & 6567.476 & 4.5 & 2081.916 \\
\hline
\end{tabular}
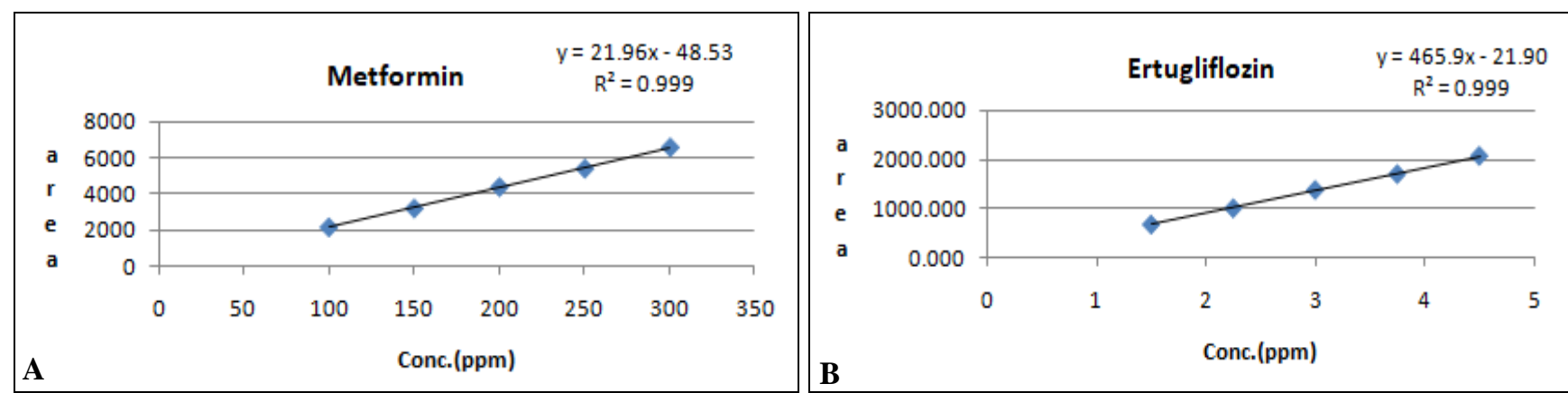

FIG. 6: GRAPH REPRESENTING CALIBRATION CURVE (A) - METFORMIN HCI AND B) - ERTUGLIFLOZIN)

Limit of Detection (LOD) and Limit of Quantitation (LOQ): The LOD and LOQ were found to be 1.04 and $9.61 \mu \mathrm{g} / \mathrm{mL}$ for MET HCL and 0.0007 and $0.006 \mu \mathrm{g} / \mathrm{mL}$ for ERT. THE results are given in Table 3.

TABLE 3: LOD AND LOQ

\begin{tabular}{ccc}
\hline Drug & LOD & LOQ \\
\hline Metformin $\mathrm{HCl}$ & $1.04 \mu \mathrm{g} / \mathrm{mL}$ & $0.0007 \mu \mathrm{g} / \mathrm{mL}$ \\
Ertugliflozin & $9.61 \mu \mathrm{g} / \mathrm{mL}$ & $0.006 \mu \mathrm{g} / \mathrm{mL}$ \\
\hline LOD = limit of detection, LOQ = limit of quantitation
\end{tabular}

TABLE 4: INTRADAY PRECISION DATA FOR ESTIMATION OF MET AND ERT

\begin{tabular}{|c|c|c|c|c|c|c|c|c|}
\hline & & MET H & & & & ERT & & \\
\hline S. no. & Conc. $\mu \mathrm{g} / \mathrm{mL}$ & Area & SD" & $\% \mathrm{RSD}^{* *}$ & Conc. $\mu \mathrm{g} / \mathrm{mL}$ & Area & SD ${ }^{*}$ & \% RSD \\
\hline \multirow[t]{3}{*}{1} & 50 & 2134.69 & 25.292 & 0.58 & 1.5 & 677.7 & 9.623 & 1.428 \\
\hline & 50 & 2160.4 & & & & 662.98 & & \\
\hline & 50 & 2166.92 & & & & 681.08 & & \\
\hline \multirow[t]{3}{*}{2} & 100 & 4325.68 & 20.104 & 0.308 & 3 & 1379.2 & 15.635 & 1.138 \\
\hline & 100 & 4361.45 & & & & 1356.24 & & \\
\hline & 100 & 4374.55 & & & & 1386.11 & & \\
\hline \multirow[t]{3}{*}{3} & 150 & 6521.85 & 20.104 & 0.308 & 4.5 & 2023.19 & 29.888 & 1.452 \\
\hline & 150 & 6534.7 & & & & 2071.54 & & \\
\hline & 150 & 6495.28 & & & & 2077.8 & & \\
\hline
\end{tabular}

*Standard deviation**\% relative standard deviation

Precision:

Method Precision / Repeatability: The \% RSD value for six replicate injection of an unknown concentration of ERT $3 \mu \mathrm{g} / \mathrm{mL}$ and MET HCL 200 $\mu \mathrm{g} / \mathrm{mL}$ carried out on the same day was found to be $<2 \%$ which indicate that the method repeatable. The results for method precision are given in Table 4. 
System Precision / Intermediate Precision: into the HPLC system and was analyzed and they Intermediate precision was determined by were found within the acceptable limit (\% RSD) measuring the peak area of six replicate was inject intermediate precision given in Table 5.

TABLE 5: INTERDAY PRECISION DATA FOR ESTIMATION OF MET AND ERT

\begin{tabular}{|c|c|c|c|c|c|c|c|c|}
\hline & & MET & & & & EI & & \\
\hline S. no. & Conc. $\mu \mathrm{g} / \mathrm{mL}$ & Area & SD* & $\%$ RSD $^{* * *}$ & Conc. $\mu \mathrm{g} / \mathrm{mL}$ & Area & SD $^{*}$ & $\%$ RSD $^{* * *}$ \\
\hline 1 & 50 & 2136.837 & 13.781 & 0.64022 & 1.5 & 678.385 & 7.078328 & 1.049754 \\
\hline & & 2162.571 & & & & 666.111 & & \\
\hline & & 2158.252 & & & & 678.357 & & \\
\hline 2 & 100 & 4325.727 & 21.0758 & 0.48455 & 3 & 1380.585 & 16.21286 & 1.18237 \\
\hline & & 4365.814 & & & & 1352.496 & & \\
\hline & & 4357.055 & & & & 1380.57 & & \\
\hline 3 & 150 & 6500.112 & 23.3342 & 0.3582 & 4.5 & 2069.503 & 32.81717 & 1.60041 \\
\hline & & 6541.25 & & & & 2012.653 & & \\
\hline & & 6501.597 & & & & 2069.485 & & \\
\hline
\end{tabular}

*Standard deviation, ** RSD, relative standard deviation

Accuracy: The percentage recovery was calculated by preparing a standard concentration of ERT and MET HCL with concentration level of $80 \%, 100 \%$, and $120 \%$. The percentage recovery obtained was found to be in the range of $99.889 \%-99.631 \%$ for
MET $\mathrm{HCl}$ and $100.181 \%-100.814 \%$ for ERT. The acceptable limits of mean recovery are $100 \%$ $102 \%$. Good recovery of the spiked drugs was obtained at each added concentration the results are given in Table 6 and 7.

TABLE 6: ACCURACY DATA FOR MET

\begin{tabular}{ccccccc}
\hline \% level & Area of sample spike with std & Amount recovered $(\mathbf{m c g} / \mathbf{m L})$ & \% recovery & Average & SD $^{*}$ & \% RSD $^{* *}$ \\
\hline $80 \%$ & 3892.77 & 78.996 & 98.745 & & & \\
$80 \%$ & 3927.711 & 80.582 & 100.728 & 99.889 & 1.026 & 1.028 \\
$80 \%$ & 3918.322 & 80.156 & 100.195 & & & \\
$100 \%$ & 4334.353 & 99.047 & 99.047 & & & \\
$100 \%$ & 4358.51 & 100.144 & 100.144 & 99.613 & 0.549 & 0.551 \\
$100 \%$ & 4347.616 & 99.649 & 99.649 & & & \\
$120 \%$ & 4795.961 & 120.008 & 100.006 & & & \\
$120 \%$ & 4774.24 & 119.021 & 99.184 & 99.631 & 0.415 & 0.417 \\
$120 \%$ & 4787.893 & 119.641 & 99.701 & & & \\
\hline
\end{tabular}

*Standard deviation, **\% relative standard deviation

TABLE 7: ACCURACY DATA FOR ERT

\begin{tabular}{cccccc}
\hline \% level & Area of sample spike with std & Amount recovered (mcg/mL) & \% recovery & Average $^{\text {SD* }}$ & \% RSD $^{* *}$ \\
\hline $80 \%$ & 1298.166 & 1.199 & 99.894 & \\
$80 \%$ & 1294.611 & 1.191 & 99.290 & 100.181 & 1.065 \\
$80 \%$ & 1306.798 & 1.216 & 101.361 & 1.063 \\
$100 \%$ & 1447.212 & 1.503 & 100.182 & \\
$100 \%$ & 1456.853 & 1.522 & 101.493 & 100.822 & 0.656 \\
$100 \%$ & 1451.696 & 1.512 & 100.792 & \\
$120 \%$ & 1604.435 & 1.823 & 101.301 & \\
$120 \%$ & 1595.665 & 1.806 & 100.307 & 100.814 & 0.497 \\
$120 \%$ & 1600.309 & 1.815 & 100.833 & & \\
\hline
\end{tabular}

*Standard deviation, $* * \%$ relative standard deviation

TABLE 8: ROBUSTNESS DATA FOR MET

\begin{tabular}{ccccccc}
\hline S. no. & Flow rate +2 & Flow rate -2 & MP* +2 & MP. - 2 & pH +2 & pH -2 \\
\hline 1 & 4230.902 & 4501.112 & 4218.439 & 4479.887 & 4151.541 & 4439.114 \\
2 & 4282.374 & 4545.746 & 4273.793 & 4488.280 & 4194.555 \\
3 & 4308.608 & 4563.092 & 4304.293 & 4445.926 & 4212.298 \\
Avg. area & 4273.961 & 4536.650 & 4265.508 & 4471.364 & 4186.131 & 4519.246 \\
SD** & 39.530 & 31.976 & 43.522 & 22.426 & 31.242 & 42.150 \\
\%RSD*** & 0.925 & 0.705 & 1.020 & 0.502 & 0.746 & 0.939 \\
\hline
\end{tabular}

* Mobile Phase**Standard deviation, ***\% relative standard deviation 
Robustness: The method was found to be robust when minor changes were made in optimized chromatographic condition such as mobile phase flow rate $(+0.2 \mathrm{~mL} / \mathrm{min})$, M.P $(+0.2)$, and $\mathrm{pH}(+$
0.2 ). It was observed that there was no marketing change in the analytical data of the drug which indicate good reliability during normal usage. The results are given in Table 8 and $\mathbf{9}$.

TABLE 9: ROBUSTNESS DATA FOR ERT

\begin{tabular}{ccccccc}
\hline S. no. & Flow rate +2 & Flow rate -2 & MP* +2 & MP. - 2 & pH +2 & pH -2 \\
\hline 1 & 1348.702 & 1434.725 & 1345.997 & 1377.816 & 1318.788 & 1417.948 \\
2 & 1356.931 & 1395.881 & 1330.659 & 1411.576 & 1302.794 & 1401.004 \\
3 & 1365.275 & 1445.626 & 1363.905 & 1430.417 & 1329.980 \\
Avg. area & 1356.969 & 1425.411 & 1346.854 & 1406.603 & 1317.187 & 1416.934 \\
SD** & 8.287 & 26.148 & 16.640 & 26.651 & 13.664 & 15.447 \\
\%RS *** & 0.611 & 1.834 & 1.235 & 1.895 & 1.037 & 1.090 \\
\hline
\end{tabular}

* Mobile Phase ${ }^{* *}$ Standard deviation, $* * * \%$ relative standard deviation

CONCLUSION: The combined dosage form of MET $\mathrm{HCl}$ and ERT is used in the treatment of diabetes. Various methods are reported in combination with another drug, but no HPLC method is available for the estimation of MET HCL and ERT combination. HPLC method for the estimation of these simultaneously has been developed and validated according to the $\mathrm{ICH}$ guideline. All the validation parameter including system suitability, linearity, accuracy, precision, LOD, LOQ, and robustness were within the recommended limits of the $\mathrm{ICH}$.

The optimized chromatogram parameters were established appropriately with mobile phase buffer $(\mathrm{pH})$ : methanol $(65: 35)$. Inertsil C18 $(250 \times 4.6$ $\mathrm{mm}$ ) column, mobile phase buffer (potassium dihydrogen $\mathrm{pH}$ 6.8): methanol $(65: 35 \mathrm{v} / \mathrm{v})$ with flow rate $1.0 \mathrm{~mL} / \mathrm{min}$ and injection volume $20 \mu \mathrm{L}$. The detection was carried out at wavelength 220 $\mathrm{nm}$. It was found to be simple, precise and accurate. The $\%$ RSD also $<2 \%$ showing high degree of precision of the proposed method. The proposed method can be used for routine analysis of MET $\mathrm{HCl}$ and ERT combine dosage form.

ACKNOWLEDGEMENT: The authors are thankful for presser JUII'S G. M. Vastanvi, principal, and guide for their encouragement and support we also wish to thanks Mr. Ketan Patel molecule laboratory.

CONFLICTS OF INTEREST: Authors does not have a conflict of Interest

\section{REFERENCES:}

1. Drug profile for Ertugliflozin available https://www.drugs. com/ppa/ertugliflozin.htmL [last access in 03 march 2019]
2. Frias JP: Fixed-dose combination of ertugliflozin and metformin hydrochloride for the treatment of type 2 diabetes. Expert review of endocrinology \& metabolism, Doi: 10.1080/17446651.2019.1571908.

3. Drug profile for Ertugliflozin available https://www. drugs.com/mtm/ertugliflozin.htmL [last access in 03 march 2019]

4. Drug profile for Metformin $\mathrm{HCl}$ available https://www. drugs.com/pro/metformin.html

5. Drug profile for Metformin $\mathrm{HCl}$ available https://www. drugs.com/metformin.html [last access in 03 march 2019]

6. Segluromet (Ertugliflozin and metformin hydrochloride) Prescribing Information. Whitehouse Station, NJ: Merck \& Co. Inc; 2017.

7. Frias JP: Fixed-dose combination of Ertugliflozin and metformin hydrochloride for the treatment of type 2 diabetes. Expert Review of Endocrinology \& Metabolism. DOI: $10.1080 / 17446651.2019 .1571908$

8. Rao PV, Rao AL and Prasad SVUM: A new stabilityindicating RP-HPLC method for simultaneous estimation of ertugliflozin and sitagliptin in bulk and pharmaceutical dosage form its validation as per ICH guidelines. Indo American Jl of PharmaSciences 2018; 05(04): 2616-27.

9. Babu DC, Chetty CM and Mastanamma SK: Novel stress indicating RP-HPLC method development and validation for the simultaneous estimation of ertugliflozin and sitagliptin in bulk and its formulation. Oriental Journal of Chemistry 2018; 34(5): 2554-61.

10. Harshalatha $\mathrm{P}$, Chandrasekhar $\mathrm{KB}$ and Chandrasekhar MV: A novel RP-HPLC method for simultaneous determination of ertugliflozin and sitagliptin in bulk and tablet dosage form. International Journal of Research in Pharmaceutical Sciences 2018; 9(3): 1042-50.

11. Kavitha D, Sahoo SK, Rao PV, Nagamani M and Bhagyalaxmi C: Development and validation of RP-HPLC method for determination of metformin and sitagliptin in bulk and pharmaceutical dosage form. Journal of Applied Pharmaceutical Research 2017; 5(2): 34-39

12. Sundar PS, Tabassum I, Vasanthi R, Raja MA, Rao KNV, Dutt KR and Mahesh M: Development and validation of stability indicating RP-HPLC method for the simultaneous estimation of alogliptin and metformin in bulk and pharmaceutical dosage form. Indo American Journal of Pharmacy 2017; 3 (5): 223-33.

13. Dayyih WA, Hamad M, Mallah E, Dayyih AA, Awad R, Zakaria $\mathrm{Z}$ and Arafat $\mathrm{T}$ : Method development and validation of vildagliptin and metformin $\mathrm{HCl}$ in pharmaceutical dosage form by reverse Phase-HighPerformance Liquid Chromatography (RP-HPLC). International J of Pharma Sci and Res 2018; 9(7): 2965-72. 
14. Patil MD, Bapna M, Shah P and Khoja SS: Development and validation of analytical method for simultaneous estimation of metformin hydrochloride and teneligliptin hydrobromide hydrate in the pharmaceutical dosage form. Journal Pharmal Science Bioscie Res 2017; 7(2): 200-08.

15. Sen AK, Hinsu DN, Sen DB, Zanwar AS, Maheshwari RA and Chandrakar VR: Analytical method development and validation for simultaneous estimation of Teneligliptin Hydrobromide hydrate and Metformin hydrochloride from its pharmaceutical dosage form by three different UV spectrophotometric methods. Journal of Applied Pharmaceutical Science 2016; 6(09): 157-65.

16. Ahmed G, Al-Salami H and Dass CR: Development and validation of a new analytical HPLC method for simultaneous determination of the antidiabetic drugs metformin and gliclazide. Journal of Food and Drug Analysis 2019; 2(7): 315-322.

17. ICH. International Conference on Harmonization of Technical Requirements for Registration of Pharmaceuticals for Human Use, Validation of analytical procedure: Text and Methodology Q2 (R1); 2005 .https://www.ich.org/fileadmin/Public_Web_Site/ICH_Pro ducts/Guidelines/Quality/Q2_R1/Step4/Q2_R1_Guideline.pdf

18. ICH. Validation of Analytical Procedures: Text and Methodology. Geneva: International Conference on Harmonization, IFPMA; 1996.https://www.ema.europa. eu/en/documents/scientific-guideline/ich-q-2-r1-validation -analytical-procedures-text-methodology-step-5_en.pdf

\section{How to cite this article:}

Shafaat SW, Ahmed A, Khan GJ, Anas S and Qureshi AA: Analytical method development and validation for simultaneous estimation of ertugliflozin and metformin $\mathrm{HCl}$ in bulk and pharmaceutical dosage form by HPLC. Int J Pharm Sci \& Res 2020; 11(1): 226-32. doi: 10.13040/IJPSR.0975-8232.11(1).226-32.

All @ 2013 are reserved by the International Journal of Pharmaceutical Sciences and Research. This Journal licensed under a Creative Commons Attribution-NonCommercial-ShareAlike 3.0 Unported License.

This article can be downloaded to Android OS based mobile. Scan QR Code using Code/Bar Scanner from your mobile. (Scanners are available on Google Play store) 